\title{
Health-related quality of life and determinants in North-China urban community residents
}

\author{
Hui $\mathrm{Wu}^{1,2}{ }^{\mathbb{D}}$, Shengbo $\mathrm{Han}^{3}$, Guicheng Zhang ${ }^{1,4}$, Weidong $\mathrm{Wu}^{1^{*}}$ and Naijun Tang ${ }^{2^{*}}$
}

\begin{abstract}
Background: The objectives of this study were to investigate the HRQoL of residents living in central urban areas (CUA) and developing neighborhoods (DN) areas of North-China and to examine the relationship between health conditions and the physical and mental components of quality of life.

Methods: A stratified random sample was taken and health survey scoring system questionnaire SF-36 was used to conduct the HRQoL survey among community residents in the two selected districts in 10 cities. A general questionnaire was also administered with questions that collected general information, population demographic characteristics and health behaviours, social relationships and perception of life satisfaction.

Results: Five thousand eight hundred eighty-one questionnaires were returned from 6059 invitations with a effective response rate of $97 \%$. The residents in DN had a higher score of physical function, role limitation due to physical problems and vitality than those living in CUA. The prevalence of several chronic diseases was lower in DN's residents than CUA's residents. Age, presence/absence of chronic diseases, leisure time exercise, regular daily routine, sleep quality, appetite, family and social relationships and life satisfaction were significant determinants of HRQoL.

Conclusions: Residents living in newly developed neighborhoods in China while keeping some habits and lifestyles of their original rural communities are healthier in terms of chronic diseases and HRQoL. Together with other risk factors chronic diseases are an important determinant on HRQoL. Several healthy habits and behaviors such as having a regular daily routine and exercising during leisure time improved HRQOL in Chinese urban communities. Targeted policies of public health based on these findings can better the health-related quality of life.
\end{abstract}

Keywords: Chinese urban communities, Quality of life, Chronic diseases, SF-36

\section{Introduction}

Health-related quality of life (HRQoL) is a multifaceted concept that includes social functioning and physical and mental health status. It is an interesting and important research topic as the findings of such research provide fundamental knowledge and evidence for policy

\footnotetext{
* Correspondence: wdwu2013@126.com; tangnaijun@tmu.edu.cn

'School of Public Health, Xinxiang Medical University, 22 Qixiangtai Rd, Tianjian 300070, China

${ }^{2}$ School of Public Health, Tianjin Medical University, 601 Jinsui Rd, Xinxiang 453000, Henan, China

Full list of author information is available at the end of the article
}

makers and government administration to implement targeted policy intervention and address significant health issues that are related to people's health status and functional wellbeing. The recent rapid change in Chinese society affects a large population of about 1.4 billion, approximately one fifth of the world population. It is timely to assess HRQoL in Chinese communities, particularly in the context of rapid urbanisation [1]. These studies will provide data for implementing evidence-based interventions in health care and public health by relevant health organisations. Supplementary

(c) The Author(s). 2020 Open Access This article is licensed under a Creative Commons Attribution 4.0 International License, which permits use, sharing, adaptation, distribution and reproduction in any medium or format, as long as you give appropriate credit to the original author(s) and the source, provide a link to the Creative Commons licence, and indicate if changes were made. The images or other third party material in this article are included in the article's Creative Commons licence, unless indicated otherwise in a credit line to the material. If material is not included in the article's Creative Commons licence and your intended use is not permitted by statutory regulation or exceeds the permitted use, you will need to obtain permission directly from the copyright holder. To view a copy of this licence, visit http://creativecommons.org/licenses/by/4.0/ The Creative Commons Public Domain Dedication waiver (http://creativecommons.org/publicdomain/zero/1.0/) applies to the data made available in this article, unless otherwise stated in a credit line to the data. 
to studies conducted in developed countries, HRQoL studies in China will add valuable data from the perspective of developing countries.

During the past 30 or 40 years, standard of living, health care and public health have significantly improved as part of the economic reform in China. However, Chinese communities are also confronting new challenges in promoting physical and mental wellbeing and reducing health inequalities. Rapid urbanization and the expansion of the urban population, an increasingly aging population, increased prevalence of non-communicable chronic diseases, and severe air pollution due to early industrialization as well as internal migration have introduced new issues into Chinese communities that may adversely influence HRQoL for residents [2-4]. These concerns are a key priority in public health, however to date, only a few studies on HRQoL have been conducted in Chinese communities [5-7].

The MOS 36-item short form health survey (SF-36) has been used world-wide as a generic and coherent measure to assess HRQoL in patients and residents [8-10]. More than 40 translated versions have been applied around the world [11] and it is the standard for international quality of life assessment. The Chinese version of SF-36 was first developed and tested in American Chinese and Cantonese [12]. In 2003 a Chinese version of SF-36 for mainland Chinese was developed and validated by $\mathrm{Li}$ et al. [13], and since then it has been commonly used in Chinese communities. In the present study we used the Chinese version (mainland) of SF-36 to compare HRQoL of residents living in an older urban city central area with residents living in a newly developed urban area. The new urban area was recently transformed from a rural suburb. We also investigated which determinants and factors are associated with HRQoL in these communities.

\section{Methods}

\section{Study design}

This cross-sectional study was conducted in NorthChina to evaluate HRQoL in urban area which including Zhengzhou, Xinxiang, Luoyang, Nanyang, Shijiazhuang, Handan, Qingdao, Binzhou and Jining, 10 cities in all. A sample size of 700 was determined sufficient in each of the survey cities, using the formula $\mathrm{n}=\left(\mathrm{u}_{\alpha} \sigma / \delta\right)^{2}(\alpha$ : Type I error, $u_{\alpha:}$ standard normal distribution, when $\alpha=0.05$, $\mathrm{u}_{\alpha}=1.96$ ) with a two-sided significance of 0.05 , a HRQoL scoring error of less than 2.5 points $(\delta)$, a standard deviation $\sigma=30$ and a response rate of $80 \%$. The household was chosen as the sampling unit, using a stratified random sampling method. Taking Zhengzhou as an example, the sample is as follows: The Jinshui district was randomly selected as the central urban area
(CUA) and the Huiji district was randomly selected as the developing neighborhood (DN). Jinshui has a population of approximately 1.6 million and Huiji, a population of about three hundred thousand. We sampled two neighborhoods at random in each district, and sampled 30 ordinary households at random in each neighborhood. Thus a total of 120 families were included in this study.

The Chinese version of SF-36 V2, which was translated and validated by Professor Li Lu of Zhejiang University, was used for the present study [13]. In all, we investigated a total of 1200 families consisting of 6059 residents across both CUA and DN. A total of 5982 questionnaires were administered. One hundred one questionnaires were excluded due to incomplete information and 5881 questionnaires were used for further analysis.

All participants were sent a letter explaining the aim of the study, who could take part in after give consent. All respondents were told that the results of this investigation would be used for research purposes only and that all personal information was confidential. Ethics approval was obtained from the Xinxiang Medical University ethics committee and the survey was recorded from April of 2016 to January of 2018. All participants enrolled gave their written informed consent.

\section{Participants}

To be included the participants had to be aged 14 years or over, not suffering from dementia or any other deurodegenerative diseases and competent of completing the self-report questionnaires without assistance.

\section{Data collection}

This study used face-to-face questionnaire. Sociodemographic characteristics of the participants (age, gender, marital status, educational level, occupation), income, medical insurance, health related lifestyle (smoking, drinking, exercise, daily routine, appetite, sleeping), their current health status according to the ICD-10 classification,relational problem(s) with friends or relatives were self-reported by participants and recorded.

HRQoL was assessed by the Chinese version of SF-36 V2 questionnaire, which are divided into eight dimensions: Physical Function (PF), Role limitations due to Physical problems (RP), Bodily Pain (BP), General Health $(\mathrm{GH})$, Vitality (VT), Social Function (SF), Role limitations due to Emotional problems (RE) and Mental Health $(\mathrm{MH})$. The first four dimensions are defined as Physical Health Components (PHC) while the last four dimensions are defined as Mental Health Components (MHC). 


\section{Statistical analyses}

The data from the survey was logged using Epidata 3.1 and statistical analysis was performed using SPSS version 20.0 software (SPSS Inc., Chicago, IL, USA). The comparison for categorical and continuous variables between CUA and DN was performed using Chi-square tests and independent samples $\mathrm{T}$ tests, respectively. We followed the recommendations of Wagner AK et al. [14] for our scoring calculations on HRQoL. To compare the scores of the 8 dimensions and 2 summary components of SF36 between residents living in CUA and DN a general linear model was used adjusted for age and gender. These HRQoL scores were also associated with presence/absence of common chronic diseases after adjusting for age, gender and the residents' areas. After adjusting for the number of common chronic diseases and other confounders the variables for demographic characteristics and health behaviours, social relationships and perception of life satisfaction were correlated with PHC and MHC (of SF-36) in a general linear model. The final stepwise regression analysis for $\mathrm{PHC}$ and MHC included variables of age, gender, residents' areas, number of chronic diseases and the significant variables of demographic characteristics and health behaviours, social relationships and perception of life. For all tests $\alpha=0.05$ was chosen as the level for statistical significance.

\section{Results}

There were 3105 participants (52.8\%) from CUA and 2776 (47.2\%) from DN. Table 1 shows the population characteristics of the participants stratified by the two areas. Compared with CUA, DN had a lower percentage of participants with tertiary or higher education, a lower percentage of participants with higher income, a lower percentage of employed and retired participants and a higher percentage of participants that are un-employed or housekeepers.

\section{Prevalence of chronic diseases and health-related quality of life in CUA and DN}

Ten common chronic diseases were investigated: hypertension, intervertebral disc related diseases, arthritis, heart disease, gastroenteritis, cerebrovascular disease, chronic obstructive pulmonary disease (COPD)/asthma, diabetes mellitus, cholecystitis and cholelithiasis and mental illness. Hypertension (23.3\%) and diabetes mellitus $(10.8 \%)$ were the highest crude prevalence of these 10 chronic diseases. The prevalence of hypertension, heart disease and asthma/COPD was significantly lower in DN than CUA $(19.5 \%$ vs $27.2 \%, P<$ $0.001 ; 4.8$ vs. $9.6 \%, P<0.001 ; 3.7 \%$ vs $5.4 \%, P=0.002$, respectively).
Table 1 The selected population characteristics of the community residents living in a central city area (CUA) and a developing neighbourhood (DN)

\begin{tabular}{|c|c|c|c|}
\hline & CUA $(n=3105)$ & $\mathrm{DN}(n=2776)$ & P \\
\hline Age, years & $48.8 \pm 12.6$ & $49.3 \pm 13.1$ & 0.136 \\
\hline Females: n (\%) & $1847(59.5)$ & 1693(61.0) & 0.240 \\
\hline Education level, n (\%) & & & $<0.001$ \\
\hline Tertiary or higher & 975 (31.4) & 264(9.5) & \\
\hline $\begin{array}{l}\text { Secondary or high } \\
\text { school }\end{array}$ & $1832(59.0)$ & $1810(65.2)$ & \\
\hline Primary or lower & 298 (9.6) & $702(25.3)$ & \\
\hline Marriage status, n (\%) & & & 0.292 \\
\hline Single & $624(20.1)$ & $591(21.3)$ & \\
\hline Married or cohabiting & $2195(70.7)$ & $1954(70.4)$ & \\
\hline $\begin{array}{l}\text { Divorced or widow/ } \\
\text { widower }\end{array}$ & $286(9.2)$ & $230(8.3)$ & \\
\hline Employment status, n (\%) & & & $<0.001$ \\
\hline Student & $171(5.5)$ & $144(5.2)$ & \\
\hline $\begin{array}{l}\text { Un-employed or } \\
\text { housekeeper }\end{array}$ & $807(26.0)$ & 1108 (39.9) & \\
\hline Employed & $1267(40.8)$ & $994(35.8)$ & \\
\hline Retired & $860(27.7)$ & $530(19.1)$ & \\
\hline Income, n (\%) & & & $<0.001$ \\
\hline Low & $730(23.5)$ & $836(30.1)$ & \\
\hline Middle & $1882(60.6)$ & $1549(55.8)$ & \\
\hline High & $494(15.9)$ & $391(14.1)$ & \\
\hline \multicolumn{4}{|l|}{ Insurance, n (\%) } \\
\hline No & $180(5.8)$ & $169(6.1)$ & 0.638 \\
\hline Yes & $2925(94.2)$ & 2607 (93.9) & \\
\hline Smoking, n (\%) & & & 0.109 \\
\hline No & $2270(73.1)$ & $2088(75.2)$ & \\
\hline Sometimes & $317(10.2)$ & $244(8.8)$ & \\
\hline Everyday & $519(17.7)$ & $444(16.0)$ & \\
\hline Drinking, n (\%) & & & 0.290 \\
\hline No & $2192(70.6)$ & $2007(72.3)$ & \\
\hline Sometimes & $543(17.5)$ & $469(16.9)$ & \\
\hline Often & $370(11.9)$ & $300(10.8)$ & \\
\hline Chronic disease, n (\%) & & & 0.027 \\
\hline No & $1860(59.9)$ & $1741(62.7)$ & \\
\hline Yes & $1245(40.1)$ & 1035 (37.3) & \\
\hline
\end{tabular}

DN residents had a higher mean score for 3 of 8 dimensions of the HRQoL questionnaire, adjusted for age and gender (Table 2). The mean scores of PF, RP and VT were significantly higher in residents living in DN than those in CUA. There was no significant difference between the two areas for the Physical and Mental Health Components. 
Chronic diseases and health-related quality of life scores After adjusting for confounding effects of age, gender and residents' area, we investigated the associations of presence/absence of the common chronic diseases with HRQoL scores. Mental illness was excluded due to the small number of residents $(n=30)$ who self-reported this. Table 3 shows adjusted mean scores of HRQoL in these residents with and without common chronic diseases. Residents with chronic conditions mostly had a lower quality of life scores, relative to residents without the condition, particularly for physical component domains such as PF, RP, BP and GH. Hypertension was with a more than $10 \%$ decrease in scores of RP, BP, GH and $\mathrm{PHC}$, intervertebral disc related disease in scores of $\mathrm{BP}, \mathrm{GH}$ and $\mathrm{PHC}$, arthritis in scores of RP, BP, GH and $\mathrm{PHC}$, heart disease in scores of PF, RP, BP, GH, PHC, gastroenteritis in scores of $\mathrm{BP}, \mathrm{GH}, \mathrm{MH}$ and $\mathrm{PHC}$, cerebrovascular disease in scores of PF, RP, BP, GH, RE, MH and $\mathrm{PHC}, \mathrm{COPD} /$ Asthma in scores of PF, RP, BP, RE and PHC, diabetes mellitus in scores of PF, RP, BP, GH, $\mathrm{RE}$ and $\mathrm{PHC}$ and cholecystitis and cholelithiasis in the score of $\mathrm{GH}$.

Table 4 shows the adjusted mean scores of SF-36 as function of the number of common chronic diseases that residents have. There is an inverse association between the number of chronic diseases and nearly all domains of the SF-36 with a linear significance of $P<0.001$, except for the VT and SF domains.

Demographic characteristics and health-related quality of life scores

We examined the association of social demographic characteristics with the summary HRQoL scores PHC and

Table 2 Adjusted mean scores of SF-36 of urban community residents living in a central urban area (CUA) and a developing neighbourhood (DN)

\begin{tabular}{|c|c|c|c|c|c|c|c|}
\hline & CUA $(n$ & $=3105)$ & & $\mathrm{DN}(n$ & 2776) & & \\
\hline & & $95 \% \mathrm{Cl}$ & & & $95 \% \mathrm{Cl}$ & & \\
\hline & Mean & Lower & Upper & Mean & Lower & Upper & P \\
\hline PF & 81.1 & 78.1 & 84.1 & 86.0 & 83.0 & 89.0 & 0.023 \\
\hline $\mathrm{RP}$ & 80.9 & 78.6 & 83.2 & 85.1 & 82.7 & 87.4 & 0.013 \\
\hline BP & 89.2 & 86.6 & 91.8 & 90.0 & 87.4 & 92.6 & 0.67 \\
\hline $\mathrm{GH}$ & 65.3 & 63.5 & 67.1 & 66.1 & 64.4 & 67.9 & 0.52 \\
\hline $\mathrm{VT}$ & 44.2 & 42.8 & 45.6 & 47.8 & 46.4 & 49.3 & $<0.001$ \\
\hline SF & 53.7 & 52.4 & 55.0 & 53.7 & 52.4 & 55.0 & 0.98 \\
\hline RE & 84.7 & 82.6 & 86.8 & 85.5 & 83.3 & 87.6 & 0.62 \\
\hline $\mathrm{MH}$ & 60.6 & 59.2 & 62.1 & 61.6 & 60.2 & 63.1 & 0.35 \\
\hline $\mathrm{PHC}$ & 321.0 & 314.1 & 327.8 & 328.6 & 321.8 & 335.5 & 0.12 \\
\hline $\mathrm{MHC}$ & 243.3 & 239.4 & 247.2 & 248.6 & 244.8 & 252.5 & 0.055 \\
\hline
\end{tabular}

Age and gender were adjusted for and general linear model was employed for the analysis
MHC. Education level, marriage status, employment, income and medical insurance were investigated using a general linear model before and after adjusting for the number of chronic diseases. Table 5 shows the statistical significance of these six social demographic variables. Marriage status and employment were significantly associated with PHC scores after adjusting for age, gender and residents' area. However, after adjusting for the number of chronic diseases the significance did not remain.

\section{Obesity, health behaviours, social relationships and perception of life satisfaction with health-related quality of life scores}

We also investigated the association of obesity, health behaviours, social relationships and perception of life satisfaction with the HRQoL scores of PHC and MHC. Table 6 shows the statistical significance of the 10 relevant variables: obesity, smoking, drinking, exercise, daily routine, appetite, sleeping, family relationship, social friendship and life satisfaction. Obesity and smoking and drinking behaviour were not associated with HRQoL in this population. However, leisure time exercise, daily routine habit, good appetite and sleeping quality, good family and social relationships and higher life satisfaction were strongly and positively correlated with PHC and $\mathrm{MHC}$, independent of chronic diseases. Figures 1 and 2 show adjusted mean scores of PHC and MHC, respectively, after adjusting for age, gender, residents' areas and the number of chronic diseases.

\section{Final models of stepwise regression of PHC and MHC}

Age, gender, residents' area, number of chronic diseases and significant variables of health behaviours, social relationships and perception of life satisfaction were further examined for the association with $\mathrm{PHC}$ and $\mathrm{MHC}$ using stepwise regression (Table 7). For PHC the final model includes age $(P<0.001)$, number of chronic diseases $(P<$ $0.001)$, good appetite $(P<0.001)$, regular daily routine $(P=0.009)$, leisure exercise $(P=0.036)$ and life satisfaction $(P=0.012)$. These significant variables explained $34 \%$ of the PHC variations. For MHC the final model includes age $(P=0.044)$, sleeping quality $(P=0.003)$, appetite $(P=0.002$ and life satisfaction $(P<0.001)$. The final model explained $14 \%$ of MHC variations.

\section{Discussion}

Our study found that the newly developed neighbourhoods in the 10 cities still exhibit some features (Table 1) of their origins of rural community and have a lower prevalence of several common chronic diseases such as hypertension, heart diseases and COPD/asthma compared with the old central city areas. The HRQoL was generally comparable between the city central district and the newly 


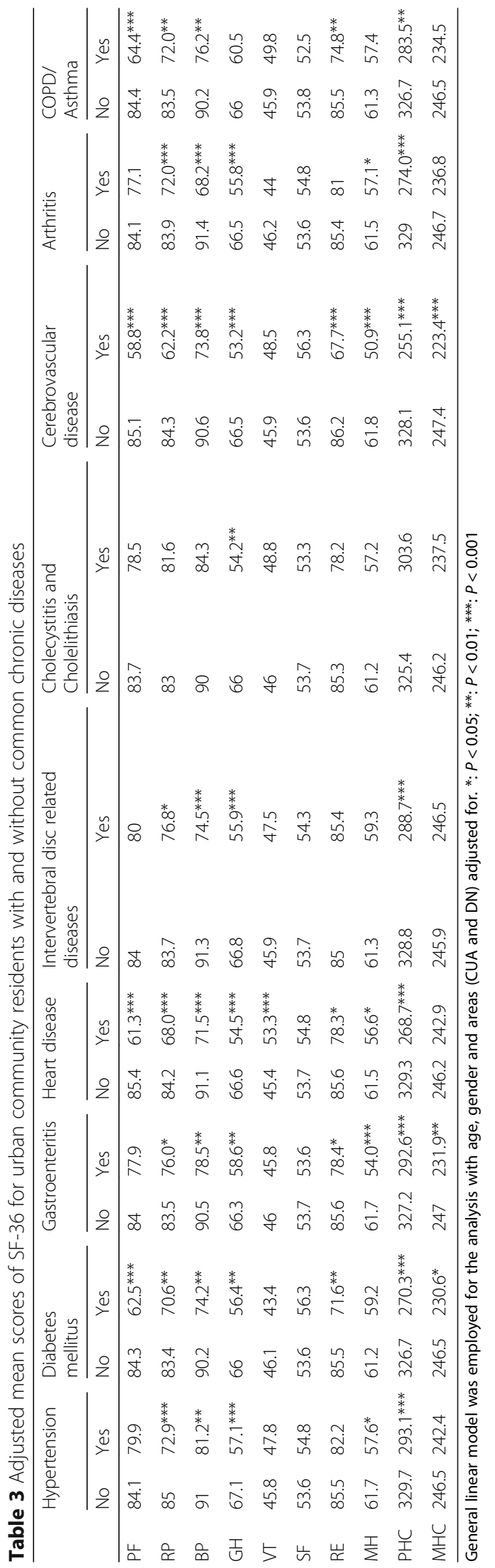


Table 4 Adjusted mean scores of SF-36 versus the number of chronic diseases reported by urban community residents

\begin{tabular}{llllll}
\hline & \multicolumn{4}{l}{ Number of chronic diseases } & \\
\cline { 2 - 4 } & 0 & 1 & $2-3$ & $>3$ & $P_{-}$linear \\
\hline PF & 86.7 & 83.3 & $76.8^{*}$ & $46.3^{* * *}$ & $<0.001$ \\
RP & 87.7 & $79.2^{* * *}$ & $70.7^{* * *}$ & $57.2^{* * *}$ & $<0.001$ \\
BP & 97.3 & $81.1^{* * *}$ & $69.1^{* * *}$ & $66.0^{* * *}$ & $<0.001$ \\
GH & 70.6 & $60.9^{* * *}$ & $52.7^{* * *}$ & $46.5^{* * *}$ & $<0.001$ \\
VT & 45.8 & 44.8 & 48.1 & $52.1^{*}$ & 0.11 \\
SF & 53.6 & 53.2 & 54.6 & 56.4 & 0.44 \\
RE & 87.9 & $82.8^{* *}$ & $77.4^{* * *}$ & $71.6^{* * *}$ & $<0.001$ \\
MH & 63.7 & $57.8^{* * *}$ & $55.2^{* * *}$ & $54.0^{* *}$ & $<0.001$ \\
PHC & 345.1 & $306.9^{* * *}$ & $271.1^{* * *}$ & $228.5^{* * *}$ & $<0.001$ \\
MHC & 251.0 & $238.6^{* * *}$ & $235.3^{* *}$ & $234.1^{*}$ & $<0.001$ \\
\hline Adjusted & & & &
\end{tabular}

Adjusted for age, gender and area. General linear model was employed for the analysis and the mean scores in residents with $1,2-3$, and $>3$ chronic diseases were compared to those in residents without chronic conditions: *: $P<0.05$; **: $P<0.01 ; * * *: P<0.001$

developed neighbourhoods with slightly higher scores of physical function, role limitations due to physical problems and vitality in newly developed neighbourhoods' residents, consistent with the lower prevalences of chronic diseases in the district. According to our findings public health strategies to improve HRQoL should be developed to promote the relatively healthy environments and lifestyles in the newly developed neighbourhoods.

Considering the two investigated districts as a whole, more than one in three residents had at least one common chronic disease. This high prevalence in urban residents is consistent with the trend of a global increase of chronic diseases $[15,16]$. Slightly lower prevalence of chronic diseases in the newly developed neighbourhoods is considered due to the preservation of previous rural suburb environments and lifestyles. The risk is that without appropriate prevention strategies the prevalence of chronic diseases in newly developed neighbourhoods is likely to

Table 5 Statistical significance for associations of social demographic characteristics with the scores of physical health component (PHC) and mental health component (MHC) assessed by SF-36

\begin{tabular}{llllll}
\hline & \multicolumn{2}{l}{$\mathrm{PHC}$} & & \multicolumn{2}{l}{$\mathrm{MHC}$} \\
\cline { 2 - 3 } & $\mathrm{p} 1$ & $\mathrm{p} 2$ & & $\mathrm{p} 1$ & $\mathrm{p} 2$ \\
\hline Education & 0.21 & 0.21 & & 0.98 & 0.98 \\
Marriage\# & 0.032 & 0.09 & & 0.076 & 0.11 \\
Employment\# & 0.001 & 0.067 & & 0.87 & 0.75 \\
Income & 0.38 & 0.071 & & 0.073 & 0.063 \\
Insurance & 0.27 & 0.42 & & 0.14 & 0.17 \\
\hline
\end{tabular}

General linear model was used for the analysis. $p 1: p$ values after adjusting for age, gender and areas (CUA and DN); p2: $p$ values after adjusting for the confounders for $\mathrm{p} 1$ plus number of chronic disease. \#: 315 students were excluded in the analysis
Table 6 Statistical significance for associations of obesity, health behaviours, social relationships and perception of life satisfaction with the scores of physical health component (PHC) and mental health component (MHC) assessed by SF-36

\begin{tabular}{llllll}
\hline & \multicolumn{1}{l}{$\mathrm{PHC}$} & & $\mathrm{NHC}$ & \\
\cline { 2 - 3 } \cline { 6 - 6 } & $\mathrm{P} 1$ & $\mathrm{P} 2$ & & $\mathrm{P} 1$ & $\mathrm{P} 2$ \\
\hline Obesity & 0.81 & 0.14 & & 0.98 & 0.96 \\
Smoking & 0.12 & 0.48 & & 0.32 & 0.43 \\
Drinking & 0.24 & 0.46 & & 0.21 & 0.28 \\
Exercise & $<0.001$ & 0.001 & & 0.016 & 0.038 \\
Daily routine & $<0.001$ & $<0.001$ & & $<0.001$ & $<0.001$ \\
Appetite & $<0.001$ & $<0.001$ & $<0.001$ & $<0.001$ \\
Sleeping & $<0.001$ & $<0.001$ & $<0.001$ & $<0.001$ \\
Family relationship & 0.001 & 0.009 & & $<0.001$ & $<0.001$ \\
Friendship & $<0.001$ & $<0.001$ & & $<0.001$ & 0.001 \\
Life satisfaction & $<0.001$ & $<0.001$ & $<0.001$ & $<0.001$ \\
\hline
\end{tabular}

General linear model was used for the analysis. p1: $p$ values after adjusting for age, gender and areas (CUA and DN); p2: $p$ values after adjusting for the confounders for $\mathrm{p} 1$ plus number of chronic disease

increase to the levels observed in the city central areas. It is likely that the urbanisation and industrialization in China may bring about a significant increase of incidence of chronic diseases in Chinese communities [16]. Therefore appropriate prevention and management strategies for chronic diseases should be implemented in these Chinese urban communities and corresponding allocations of public health resources should be considered.

The HRQoL of persons with chronic diseases was generally poorer than for persons without chronic diseases and patients affected by more than one chronic disease had further reduced HRQoL scores, particularly for physiological health. Consistent with our results recent studies also reported significant influences of chronic diseases on HRQoL in Chinese community residents [17-19]. All 9 common chronic diseases analysed in the present study were associated with significantly reduced scores of some domains assessed by SF-36 with an up to $31 \%$ in reduction of physical function (PF) for cerebrovascular disease. In our final stepwise regression model the presence of one more chronic diseases was accompanied with a reduction of 30.6 units in PHC scores. The linear correlation between the number of common chronic diseases and the HRQoL domains were all significant $(p<0.001)$ except for vitality $(\mathrm{VT})$ and social function (SF). Our investigation has shown strong associations between chronic diseases and poor HRQoL. Therefore prevention and management of chronic diseases should be a key priority in community health in order to maintain a high level of HRQoL for Chinese urban communities.

Obesity is an important risk factor for many chronic diseases such as hypertension, coronary heart disease and 


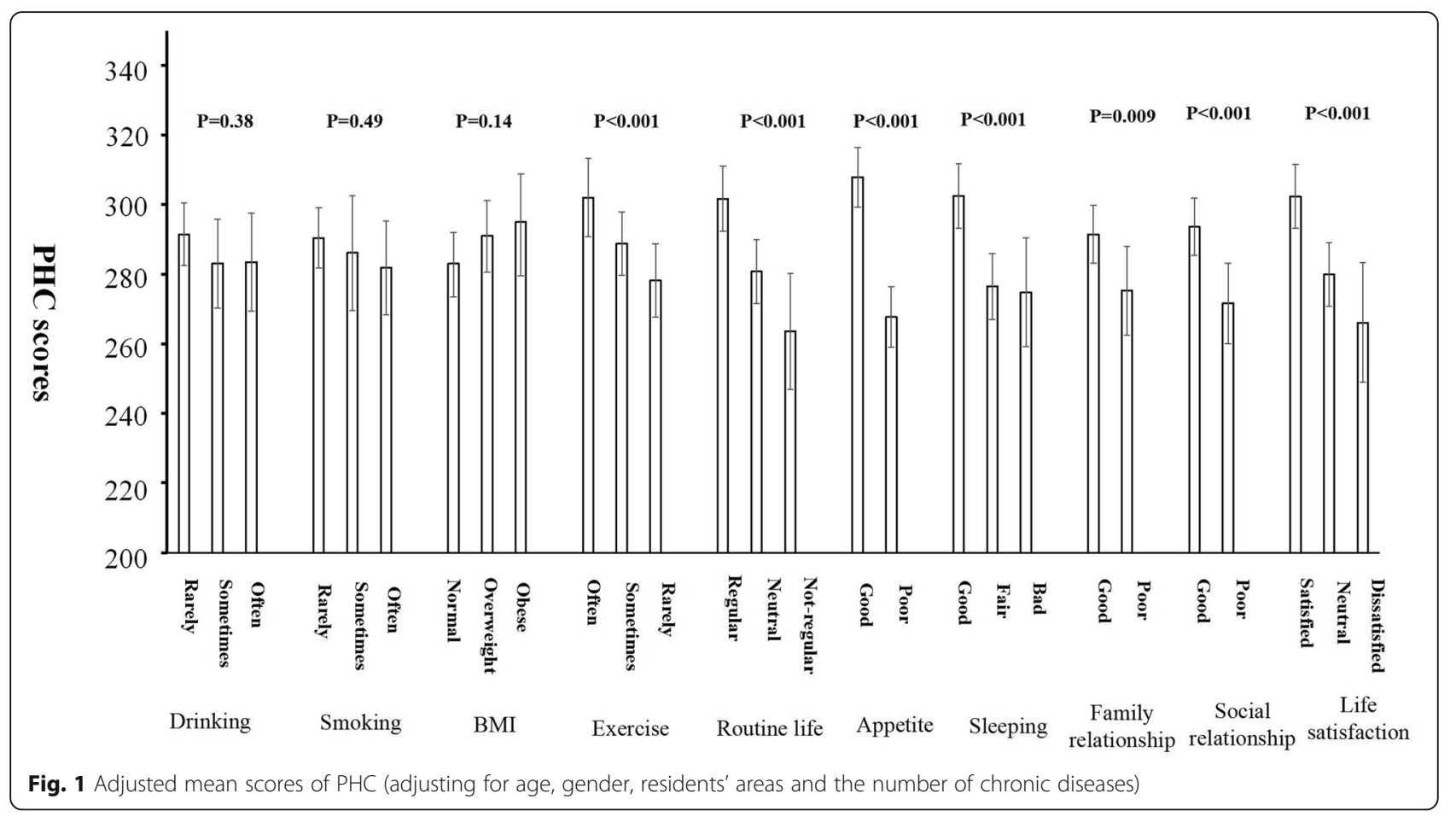

diabetes. Studies have shown that obese persons have a reduced HRQoL compared to those with normal body weight $[20,21]$ although this is not always consistent [22]. In our study obesity was not associated with HRQoL. To explain the absent relationship between obesity and fitness, the obesity paradox hypothesis has been proposed, which may partly explain our findings $[22,23]$. However, considering the positive correlation of obesity and urbanization in modern life [24] as well as the role of obesity in the development of many chronic diseases $[16,25,26]$ the influence of

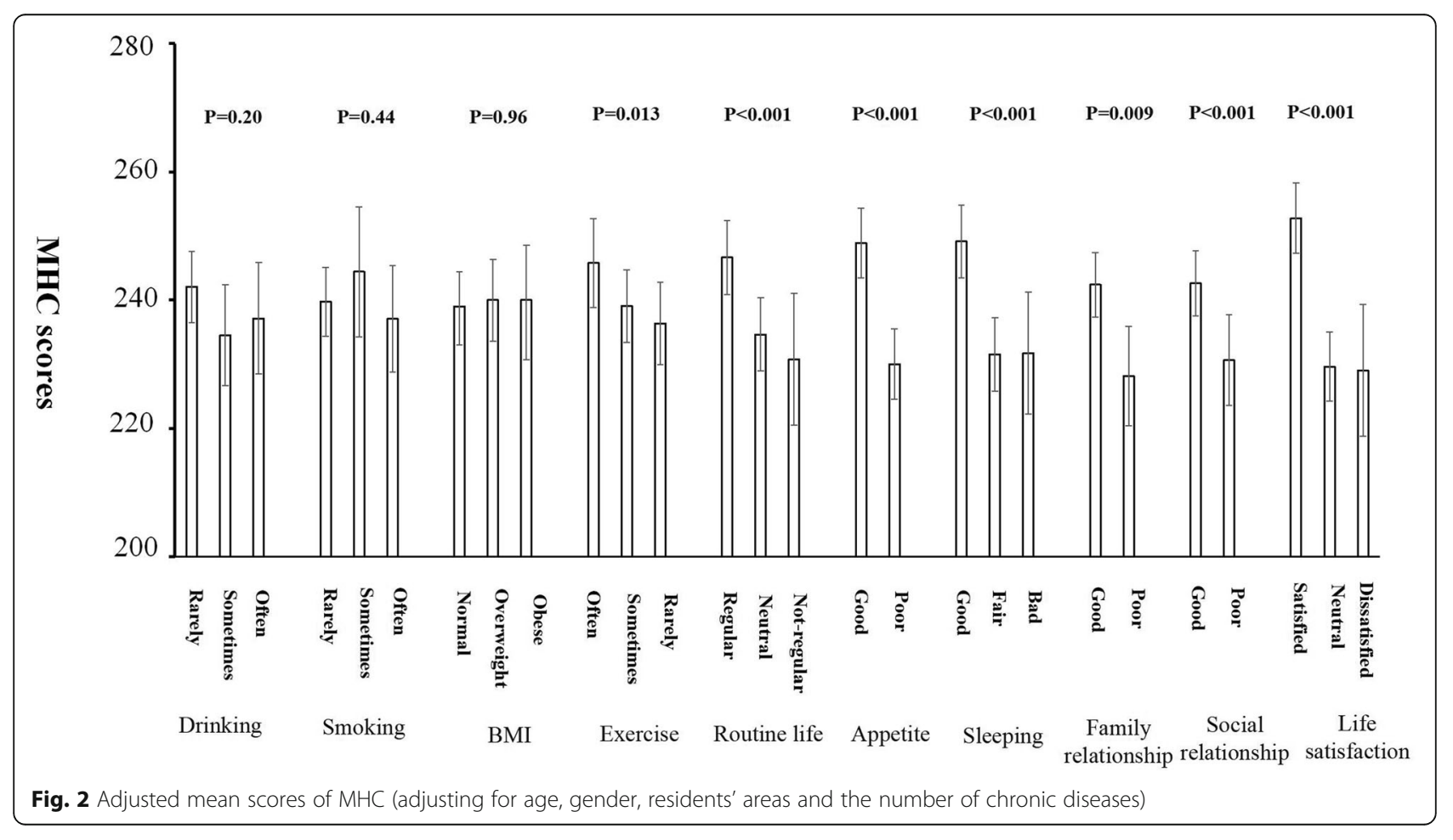


Table 7 Final regression model of PHC and MHC

\begin{tabular}{|c|c|c|c|c|c|}
\hline Determinants & Unit/coding & Beta & Standard error & $P$ & Adjusted R square \\
\hline PHC & & & & & 0.34 \\
\hline Age & Years & -0.50 & 0.14 & $<0.001$ & \\
\hline Number of Chronic diseases & $0,1,2,3$ & -30.6 & 3.0 & $<0.001$ & \\
\hline Appetite & 0,1 & 31.6 & 4.7 & $<0.001$ & \\
\hline Regular daily routine & $0,1,2$ & 9.6 & 3.7 & 0.009 & \\
\hline Leisure time exercise & $0,1,2$ & 6.3 & 3.0 & 0.036 & \\
\hline Life satisfaction & $0,1,2$ & 9.1 & 3.6 & 0.012 & \\
\hline MHC & & & & & 0.14 \\
\hline Age & Years & 0.15 & 0.07 & 0.044 & \\
\hline Sleeping quality & $0,1,2$ & 6.9 & 2.3 & 0.003 & \\
\hline Appetite & $0,1,2$ & 9.9 & 3.1 & 0.002 & \\
\hline Life satisfaction & $0,1,2$ & 13.8 & 2.2 & $<0.001$ & \\
\hline
\end{tabular}

obesity on HRQoL should not be ignored, particularly for obesity in young and middle age adults. We did not find that smoking or drinking had a significant influence on HRQoL. This is consistent with the findings by Song et al. [6] among urban community residents in an industrial city located in the northeast of China. Smoking and drinking has been consistently accepted as risk factors for many chronic diseases but are rarely correlated with HRQoL [27, 28]. However, bearing in mind the adverse effects of these behaviors on health and the significant correlation of bad health and poor HRQoL, smoking cessation and alcohol abstinence should continually be advocated as part of public health education. We also did not find any influence of sociodemographic and socioeconomic variables such as education levels, income, insurance, marital status and employment on HRQoL in the urban community population. HRQoL is a multifactorial complex concept, and the interrelationship of many factors can influence it. The findings of our study does not suggest that these sociodemographic and socioeconomic variables are significant determinants for HRQoL. However, further investigation is required to dissect the complex interactions of these variables and other factors.

It is envisaged that age is an important determinant of HRQoL. In our final stepwise regression models age, was negatively associated with physical health and positively with mental health. Thus age-specific health promotion for better HRQoL is necessary. Sleep quality and appetite are two health behaviors that were strongly associated with HRQoL, particularly for mental health. It indicates that sleeping well and good appetite are important for HRQoL. Any health problems that disturb sleep pattern or reduce appetite need to be attended to for a better HRQoL. Daily routines and regular leisure time exercise are two habits that were significantly associated with higher scores of
HRQoL for physical and mental health. These positive habits should be extensively promoted at the community level. Currently, the exercise routine of square dancing set to music in squares, parks and any open spaces is popular in Chinese communities [29], particularly for retirees and unemployed residents. This practice is expected to be a good health promotion strategy to increase physical activity and maintain a daily routine, and could be encouraged in the Chinese communities to increase HRQoL. Our data also show that life satisfaction is an important determinant for HRQoL of physical and mental health. To hold an optimistic attitude to manage chronic diseases and to cope well with adverse life events will be of benefit for HRQoL.

\section{Conclusion}

Residents living in newly developed neighborhoods have a lower prevalence of chronic diseases and higher HRQoL scores relative to residents living in the old city central community. Chronic diseases are an important determinant on HRQoL. Several healthy habits and behaviors can be promoted to have a better HRQoL in Chinese urban communities. Targeted policies of public health based on the findings in the present study might improve the health-related quality of life.

\section{Limitation}

There are limitations in the present study. This is a cross-sectional study that only can identify associations. The causality of these associations needs to be investigated by a longitudinal study. In addition, we didn't require the diagnosis certificate or case of the accident in the course of the investigation, and there is a certain information bias. 


\section{Abbreviations}

HRQoL: Health-related quality of life; CUA: Central urban area; DN: Developing neighborhood; SF-36: The MOS 36-item short form health survey; PF: Physical Function; RP: Role limitations due to Physical problems; BP: Bodily Pain; GH: General Health; VT: Vitality; SF: Social Function; RE: Role limitations due to Emotional problems; MH: Mental Health; PHC: Physical Health Components; MHC: Mental Health Components; COPD: Chronic obstructive pulmonary disease

\section{Acknowledgements}

The authors thank MS. Helen Brown for her editorial assistance.

\section{Authors' contributions}

HW, WDW conceived and elaborated the study, HW wrote the this manuscript under the supervision of WDW and NJT. All authors participated in the data analysis as well as read and gave their approval to the final version of this manuscript submitted for publication.

\section{Funding}

This study without financial support.

\section{Availability of data and materials}

Data is available on request from the corresponding author.

\section{Ethics approval and consent to participate}

The study was in accordance with the ethical standards of Xinxiang Medical University, Henan, China. Informed consent was obtained from all individual participants included in the study. The study was approved by the ethics committee at Xinxiang Medical University.

\section{Consent for publication}

Not applicable.

\section{Competing interests}

The authors declare no competing non-financial/financial interests.

\section{Author details}

'School of Public Health, Xinxiang Medical University, 22 Qixiangtai Rd, Tianjian 300070, China. ${ }^{2}$ School of Public Health, Tianjin Medical University, 601 Jinsui Rd, Xinxiang 453000, Henan, China. ${ }^{3}$ Zhengzhou Traditional Chinese Medicine Hospital, 65 wenhuagong Rd, Zhongyuan District, Zhengzhou 450002, Henan, China. ${ }^{4}$ School of Public Health, Curtin University, Roberts Rd, Subiaco WA, Perth 6008, Australia.

Received: 4 September 2019 Accepted: 30 July 2020

\section{Published online: 14 August 2020}

\section{References}

1. Zhao S, Zhou D, Zhu C, Sun Y, Wu W, Liu S. Spatial and temporal dimensions of urban expansion in China. Environ Sci Technol. 2015:49:9600-9.

2. Lancet T. (Barely) living in smog: China and air pollution. Lancet. 2014;383:845.

3. Rydin Y, Bleahu A, Davies M, Davila JD, Friel S, De Grandis G, Groce N, Hallal PC, Hamilton I, Howden-Chapman P, et al. Shaping cities for health: complexity and the planning of urban environments in the 21st century. Lancet. 2012;379:2079-108.

4. Bai X. The urban transition in China: trends, consequences and policy implications. In The new global frontier: cities, poverty and environment in the 21stCentury. Edited by Martine; G, McGranahan; G, Montgomery M, CastillaFernandez R. London: IIED/UNFPA and Earthscan Publications; 2008.

5. Lei $P, X u$ L, Nwaru Bl, Long Q, Wu Z, Song T, Ding YW, Sun Y, He YN, Qi DJ, et al. Social networks and health-related quality of life among Chinese old adults in urban areas: results from 4th National Household Health Survey a populationbased study on health-related quality of life among urban community residents in Shenyang, northeast of China. Public Health. 2016;131:27-39.

6. Song T, Ding YW, Sun Y, He YN, Qi DJ, Wu Y, Wu B, Lang L, Yu K, Zhao X, et al. A population-based study on health-related quality of life among urban community residents in Shenyang, Northeast of China. BMC Public Health. 2015;15:921.

7. Zhang Y, Zhou Z, Gao J, Wang D, Zhang Q, Zhou Z, Su M, Li D. Healthrelated quality of life and its influencing factors for patients with hypertension: evidence from the urban and rural areas of Shaanxi Province, China. BMC Health Serv Res. 2016:16:277.

8. Kazmi SS, Krog AH, Berge ST, Sundhagen JO, Sahba M, Falk RS. Patientperceived health-related quality of life before and after laparoscopic aortobifemoral bypass. Vasc Health Risk Manag. 2017;13:169-76.

9. Onal S, Oray M, Yasa C, Akman M, Uludag G, Koc Akbay A, Tugal-Tutkun I. Screening for Depression and Anxiety in Patients with Active Uveitis. Ocul Immunol Inflamm. 2018;26(7):1-16.

10. Yarlas AS, White MK, Yang M, Saris-Baglama RN, Bech PG, Christensen T. Measuring the health status burden in hemodialysis patients using the SF36(R) health survey. Qual Life Res. 2011:20:383-9.

11. Jenkinson C, Stewart-Brown S, Petersen S, Paice C. Assessment of the SF-36 version 2 in the United Kingdom. J Epidemiol Community Health. 1999;53:46-50.

12. Lam CL, Gandek B, Ren XS, Chan MS. Tests of scaling assumptions and construct validity of the Chinese (HK) version of the SF-36 health survey. J Clin Epidemiol. 1998;51:1139-47.

13. Li L, Wang H, Shen Y. Chinese SF-36 health survey: translation, cultural adaptation, validation, and normalisation. J Epidemiol Community Health. 2003:57:259-63.

14. Wagner AK, Gandek B, Aaronson NK, Acquadro C, Alonso J, Apolone G, Bullinger M, Bjorner J, Fukuhara S, Kaasa S, et al. Cross-cultural comparisons of the content of SF-36 translations across 10 countries: results from the IQOLA project. International quality of life assessment. J Clin Epidemiol. 1998:51:925-32.

15. Vos T, Barber R, Bell B, Bertozzi-Villa A, Biryukov S, Bolliger I, Charlson F, Davis A, Degenhardt L, Dicker D, et al. Global, regional, and national incidence, prevalence, and years lived with disability for 301 acute and chronic diseases and injuries in 188 countries, 1990-2013: a systematic analysis for the global burden of disease study 2013. Lancet. 2015;386:743-800.

16. Wang $Y$, Wang $L$, Qu W. New national data show alarming increase in obesity and noncommunicable chronic diseases in China. Eur J Clin Nutr. 2017;71:149-50

17. Chen $Y$, Sun G, Guo X, Chen S, Chang Y, Li Y, Sun Y. Factors affecting the quality of life among Chinese rural general residents: a cross-sectional study. Public Health. 2017:146:140-7.

18. Chen Z, Wang Y, Zhang Q, Wang Q, Feng X. Influencing Factors of Healthrelated Quality of Life:An Analysis Based on the National Health Services Survey in Jilin Province,2013. Zhongguo Yi Xue Ke Xue Yuan Xue Bao. 2017;39:261-5.

19. Lee SW, Lee TY, Lien HC, Peng YC, Yeh HJ, Chang CS. Correlation between symptom severity and health-related life quality of a population with Gastroesophageal reflux disease. Gastroenterology Res. 2017;10:78-83.

20. Park S. Pathways linking obesity to health-related quality of life. Qual Life Res. 2017;26(8):2209-18.

21. Tamura LS, Cazzo E, Chaim EA, Piedade SR. Influence of morbid obesity on physical capacity, knee-related symptoms and overall quality of life: A crosssectional study. Rev Assoc Med Bras (1992). 2017:63:142-7.

22. Zhu Y, Wang Q, Pang G, Lin L, Origasa H, Wang Y, Di J, Shi M, Fan C, Shi H. Association between body mass index and health-related quality of life: the "obesity paradox" in 21,218 adults of the Chinese general population. PLoS One. 2015:10:e0130613.

23. Doehner W, Clark A, Anker SD. The obesity paradox: weighing the benefit. Eur Heart J. 2010;31:146-8.

24. Hawkes C. Uneven dietary development: linking the policies and processes of globalization with the nutrition transition, obesity and diet-related chronic diseases. Glob Health. 2006:2:4.

25. Seravalle G, Grassi G. Obesity and hypertension. Pharmacol Res. 2017;122:1-7.

26. Poirier P, Giles TD, Bray GA, Hong Y, Stern JS, Pi-Sunyer FX, Eckel RH. Obesity and cardiovascular disease: pathophysiology, evaluation, and effect of weight loss. Arterioscler Thromb Vasc Biol. 2006:26:968-76.

27. Byles J, Young A, Furuya H, Parkinson L. A drink to healthy aging: the association between older women's use of alcohol and their health-related quality of life. J Am Geriatr Soc. 2006;54:1341-7.

28. Soares MF, Ferreira RC, Pazzini CA, Travassos DV, Paiva SM, e Ferreira EF Individual and collective empowerment and associated factors among Brazilian adults: a cross-sectional study. BMC Public Health. 2015;15:775.

29. Kopin LA, Pearson TA. In the clinic: dyslipidemia (vol 147, pg ITC9-1, 2007). Ann Intern Med. 2008;148:407-8.

\section{Publisher's Note}

Springer Nature remains neutral with regard to jurisdictional claims in published maps and institutional affiliations. 